\title{
PENENTUAN HARGA OPSI ASIA DENGAN METODE MONTE CARLO
}

\author{
Surya Amami Pramuditya ${ }^{1}$ \\ FKIP, Universitas Swadaya Gunung Djati ${ }^{1}$, amamisurya @ fkip-unswagati.ac.id ${ }^{1}$
}

\begin{abstract}
Abstrak
Opsi adalah kontrak antara holder dan writer dimana writer memberikan hak (bukan kewajiban) kepada holder untuk membeli atau menjual aset dari writer dengan harga tertentu (strike price) dan pada waktu yang telah ditentukan dimasa datang (maturity time). Opsi Asia termasuk pada opsi path dependent. Artinya payoff opsi Asia tidak hanya bergantung pada harga saham saat maturity time saja, tetapi merupakan rata-rata harga saham selama masa jatuh temponya dan disimbolkan $A$ (average). Monte Carlo pada dasarnya digunakan sebagai prosedur numerik untuk menaksir nilai ekspektasi pricing product derivative. Teknik yang digunakan adalah Monte Carlo standar dan reduksi varians. Hasilnya diperoleh harga opsi Asia call dan put untuk kedua teknik dengan selang kepercayaan $95 \%$. Teknik reduksi varians terlihat lebih cepat memperkecil selang kepercayaan $95 \%$ dibandingkan metode standar.
\end{abstract}

Kata kunci: opsi,, Asia, Monte Carlo

\begin{abstract}
Option is a contract between a holder and a writer in which the writer grants the rights (not obligations) to the holder to buy or sell the assets of the writer at a certain price (strike price) at maturity time. Asian options are included in the dependent path option. This means that Asia's payoff option depends not only on the stock price at maturity time, but it is the average stock price during its maturity and symbolized A (average). Monte Carlo is basically used as a numerical procedure to estimate the expected value of pricing product derivatives. The techniques used are the standard Monte Carlo and variance reduction. The result obtained the Asia call option price and put for both techniques with $95 \%$ confidence interval. The variance reduction technique looks faster reducing $95 \%$ confidence interval than standard method.
\end{abstract}

Keyword: option, Asian, Monte Carlo

\section{Pendahuluan}

Hull [2] mendefinisikan opsi sebagai kontrak antara holder dan writer dimana writer memberikan hak (bukan kewajiban) kepada holder untuk membeli atau menjual suatu aset dari writer dengan harga tertentu (strike atau exercise price) dan pada waktu yang telah ditentukan dimasa datang (expiry date atau maturity time) [4][5]. Salah satu jenis opsi adalah opsi Asia. Opsi Asia termasuk pada opsi path dependent [4]. Artinya payoff opsi Asia tidak hanya bergantung pada harga saham saat maturity time saja. Di sini payoff opsi Asia merupakan rata-rata harga saham selama masa jatuh temponya dan disimbolkan $A$ (average).

Metode Monte Carlo pada dasarnya digunakan sebagai prosedur numerik untuk menaksir nilai ekspektasi dari suatu peubah acak sehingga metoda ini dapat digunakan untuk permasalahan pricing product derivative jika direpresentasikan sebagai nilai ekspektasinya. Prosedur simulasi melibatkan generating dari peubah acak dengan suatu fungsi kepadatan dan dengan menggunakan law of large number maka rata-rata dari nilai ini dapat dinyatakan sebagai penaksir ekspektasi peubah acak tersebut. Penelitian ini bertujuan untuk mencari payoff harga opsi Asia call dan put fixed strike dan 
average strike disertai selang kepercayaan $95 \%$. Selanjutnya, dicari selang kepercayaan terkecil melalui metode Monte Carlo standard dan reduksi varians.

\section{Simulasi Monte Carlo}

Misalkan $X$ peubah acak dengan ekspektasi $E(X)=a$ dan $\operatorname{Var}(X)=b^{2}$ yang nilainya belum diketahui.

Misalkan $X_{1}, X_{2}, \ldots, X_{M}$ adalah barisan peubah acak yang berdistribusi identik dengan $X$, maka penaksir tak bias untuk $a$ [6][3] adalah

$$
a_{M}=\frac{1}{M} \sum_{i=1}^{M} X_{i}
$$

dan penaksir tak bias untuk $b^{2}$ adalah

$$
b_{M}^{2}=\frac{1}{1-M} \sum_{i=1}^{M}\left(X_{i}-a_{M}\right)^{2}
$$

Berdasarkan teorema limit pusat untuk $M \rightarrow \infty$ berlaku

$$
\frac{\sum_{i=1}^{M} X_{i}-M a}{b \sqrt{M}} \sim N(0,1)
$$

atau

Sehingga,

$$
\sum_{i=1}^{M} X_{i} \sim N\left(M a, b^{2} M\right)
$$

$$
\begin{aligned}
a_{M}-a= & \frac{1}{M} \sum_{i=1}^{M} X_{i}-a \sim N\left(0, b^{2} / M\right) \\
& \frac{a_{M}-a}{b \sqrt{M}} \sim N(0,1)
\end{aligned}
$$

Akan didapatkan taksiran interval untuk $a$. Perhatikan

$$
\begin{gathered}
P\left(\left|\frac{a_{M}-a}{b \sqrt{M}}\right| \leq 1.96\right)=0.95 \\
P\left(-1.96 \leq \frac{a_{M}-a}{b \sqrt{M}} \leq 1.96\right)=0.95 \\
P\left(a_{M}-1.96 \frac{b}{\sqrt{M}} \leq a \leq a_{M}+1.96 \frac{b}{\sqrt{M}}\right) \\
=0.95
\end{gathered}
$$

Di $\operatorname{sini} \frac{b}{\sqrt{M}}$ merupakan standard error, dengan mengambil $b \approx b_{M}$, maka

$$
\begin{gathered}
P\left(a_{M}-1.96 \frac{b_{M}}{\sqrt{M}} \leq a \leq a_{M}+1.96 \frac{b_{M}}{\sqrt{M}}\right) \\
=0.95
\end{gathered}
$$

Sehingga diperoleh selang kepercayaan $95 \%$ untuk $a$ adalah $\left[a_{M}-1.96 \frac{b_{M}}{\sqrt{M}}, a_{M}+1.96 \frac{b}{\sqrt{M}}\right]$.

Agar akurasi selang lebih akurat dapat diperoleh malalui dua cara yaitu :

1. Memperbesar simulasi $M$, tetapi hal ini memberikan waktu komputasi yang lama.

2. Mengecilkan $b_{M}$ atau mereduksi variansi dengan menggunakan kontrol variat.

\subsection{Teknik Reduksi Variansi dengan Kontrol Variat}

Taksiran selang akan semakin akurat jika lebar dari selang tersebut semakin sempit/kecil, lebar selang kepercayaan dapat dipersempit dengan cara memperbanyak sampel (menambah jumlah simulasi). Namun cara ini cukup menyulitkan karena faktor $\sqrt{M}$. Sebagai contoh, untuk mendapatkan selang kepercayaan yang lebih akurat, yaitu menyusutkan selang kepercayaan dengan faktor 10 membutuhkan sampel seratus kali lebih banyak dari semula.

Cara lain yang dapat dilakukan adalah memperkecil standar deviasi $\left(b_{M}\right)$ yang berarti memperkecil variansi [1]. Ide dari teknik ini dalah mengganti $X_{i}$ dengan barisan peubah acak yang lain yang juga identik dengan mean sama dengan $E\left(X_{i}\right)$ namun dengan variansi yang lebih kecil.

Misalkan $\theta=E(X)$ ingin ditaksir dengan simulasi Monte Carlo. Andaikan ada peubah acak lain, selain $X$ yaitu $Y$ dengan mean $E(Y)=\mu_{Y}$, kemudian akan ditunjukkan $\operatorname{var}(X)>\operatorname{var}(Y)$. Tulis peubah acak

$$
Z=X+c\left(Y-\mu_{Y}\right)
$$

maka nilai ekspektasi dari $Z$ adalah

$$
\begin{aligned}
E\left(X+c\left(Y-\mu_{Y}\right)\right) & =E(X)+c E\left(Y-\mu_{Y}\right) \\
& =\theta+c E\left(Y-\mu_{Y}\right) \\
& =\theta
\end{aligned}
$$

Sedangakan variansinya

$$
\begin{aligned}
& \operatorname{var}\left(X+c\left(Y-\mu_{Y}\right)\right)=\operatorname{var}(X+c Y) \\
& =\operatorname{var}(X)+\operatorname{var}(Y)+2 \operatorname{cov}(X, c Y) \\
& =\operatorname{var}(X)+c^{2} \operatorname{var}(Y)+2 c \operatorname{cov}(X, Y)
\end{aligned}
$$

Pilih $Y$ sedemikian rupa sehingga $\operatorname{cov}(X, Y) \neq 0$. Karena $\operatorname{var}(X), \operatorname{var}(Y), \operatorname{Cov}(X, Y)$ diketahui, maka $\operatorname{var}(Z)=f(c)$ yaitu fungsi kuadrat dalam c. Minimumkan ruas kanan pada persamaan (5) terhadap $c$ diperoleh

$$
c^{*}=\frac{-\operatorname{cov}(X, Y)}{\operatorname{var}(Y)}
$$

usahakan $\operatorname{cov}(Y, V)$ positif sehingga $c^{*}$ negatif. Dengan mengsubsitusikan persaman (6) ke persamaan (5) diperoleh 
$\operatorname{var}\left(X+c^{*}\left(Y-\mu_{Y}\right)\right)=\operatorname{var}(X)-\frac{\operatorname{cov}^{2}(X, Y)}{\operatorname{var}(Y)}$

diperoleh reduksi variansi

$$
\begin{aligned}
\frac{\operatorname{var}(Z)}{\operatorname{var}(Y)}=1- & \frac{\operatorname{cov}^{2}(X, Y)}{\operatorname{var}(Y) \operatorname{var}(X)} \\
& =1-\operatorname{corr}^{2}(X, Y)
\end{aligned}
$$

selanjutnya pilih

$$
Y=\sum_{i=1}^{M} S(n)_{i}
$$

dan lakukan $k$ simulasi untuk $X$ dan $Y$ diperoleh $X_{i}$ dan $Y_{i}(i=1,2, \ldots, k)$. Tulis

$$
\begin{gathered}
\bar{X}=\frac{1}{k} \sum_{i=1}^{k} X_{i} \\
\bar{Y}=\frac{1}{k} \sum_{i=1}^{k} Y_{i} \\
\widehat{\operatorname{cov}}(X, Y)=\frac{1}{k-1} \sum_{i=1}^{k}\left(X_{i}-\bar{X}\right)(Y-\bar{Y}) \\
\widehat{\operatorname{arr}}(X, Y)=\frac{1}{k-1} \sum_{i=1}^{k}\left(Y_{i}-\bar{Y}\right)
\end{gathered}
$$

Peubah acak pembanding memiliki mean sampel

$$
\hat{\theta}=\frac{1}{k} \sum_{i=1}^{k}\left(X_{i}+\hat{c}^{*}\left(Y-\mu_{Y}\right)\right)
$$

\subsection{Model Harga Saham}

Misalkan model pergerakan harga saham [3] [2] [4] [5] adalah

$$
S(T)=S_{0} e^{\left(r-\frac{1}{2} \sigma^{2}\right) T+\sigma \sqrt{T} Z}
$$

dengan $Z \sim N(0,1)$

serta $=\frac{1}{N}$, dimana $N$ merupakan banyak hari kerja dalam 1 tahun.

Selanjutnya model saham ini menghasilakan ekspektasi dari peubah acak [4][5]

$$
C=e^{-r T} \operatorname{maks}\left\{S_{0} e^{\left(r-\frac{1}{2} \sigma^{2}\right) T+\sigma \sqrt{T} Z}-K, 0\right\}
$$

yaitu nilai opsi call Eropa saat $T$ dihitung di $t=0$.

\subsection{Opsi Asia}

Payoff dari Asian option ditentukan dari nilai rata-rata untuk tiap kasusnya [2][6], yaitu:
- Average price Asian Call (fixed strike price)

$$
C(S, T)=\operatorname{maks}\left(\frac{1}{T} \int_{0}^{T} S(\tau) d \tau-K, 0\right)
$$

- Average price Asian Put ((fixed strike price))

$$
P(S, T)=\operatorname{maks}\left(E-\frac{1}{T} \int_{0}^{T} S(\tau) d \tau, 0\right)
$$

- Average Strike Price Asian Call

$$
C(S, T)=\operatorname{maks}\left(S(T)-\frac{1}{T} \int_{0}^{T} S(\tau) d \tau, 0\right)
$$

- Average Strike Price Asian Put

$$
P(S, T)=\operatorname{maks}\left(\frac{1}{T} \int_{0}^{T} S(\tau) d \tau-S(T), 0\right)
$$

Pandang

$$
\int_{0}^{T} S(\tau) d \tau \approx \Delta t \sum_{j=1}^{N} S_{j}
$$

dimana $\mathrm{N}$ adalah banyaknya partisi dan ingat bahwa $T=N \Delta T$, maka

$$
\int_{0}^{T} S(\tau) d \tau=\frac{1}{N \Delta t} \Delta t \sum_{j=1}^{N} S_{j}=\frac{1}{N} \sum_{j=1}^{N} S_{j}
$$

Sehingga penggunaan Monte Carlo untuk Asian Call Option memiliki payoff [3]

$$
C_{i}(S, T)=\operatorname{maks}\left(\frac{1}{N} \sum_{j=1}^{N} S_{j}-K, 0\right)
$$

atau

$$
C_{i}(S, T)=\operatorname{maks}\left(S(T)-\frac{1}{N} \sum_{j=1}^{N} S_{j}, 0\right)
$$

untuk $i=1,2, \ldots, M$.

Berdasarkan persamaan (9), persamaan (10) dan (11) dapat dituliskan

$$
\begin{gathered}
\text { Vcprice }=\exp \left(-r \frac{n}{N}\right)\left(\frac{1}{n} \sum_{j=1}^{n} S_{j}\right. \\
-K, 0)^{+}
\end{gathered}
$$

atau

$$
\begin{array}{r}
\text { Vcstrike }=\exp \left(-r \frac{n}{N}\right)\left(S_{T}\right. \\
\left.-\frac{1}{n} \sum_{j=1}^{n} S_{j}, 0\right)^{+}
\end{array}
$$




\subsection{Algoritma Metode Monte Carlo}

Berikut merupakan algoritma menentukan harga opsi Asia dengan Metode Monte Carlo [6].

Tabel 1. Harga Saham

Input: $S_{0}, K, r, \sigma, n, N, M$
Bangkitkan faktor acak $z(M, n)$
Hitung $E(X)=m u=\left(r-\frac{1}{2} \sigma^{2}\right) / N$
$\quad \operatorname{Var}(X)=\operatorname{dev}=\sigma / \sqrt{N}$
Untuk $i=1,2, \ldots, M$ dan $j=1,2, \ldots, n$
$\bullet \quad$ Untuk $j=1, x(i, j)=m u+\operatorname{dev} *$
$\quad z(i, j)$
- Untuk $j=2, \ldots, n, x(i, j)=x(i, j-$
$\quad 1)+(m u+\operatorname{dev} * z(i, j))$
Harga saham $S_{b}(i, j)=S_{0} * \exp (x(i, j))$

Tabel 2. Opsi Asia

Bangun harga saham $S_{b}$

Hitung $A$ mean $S_{b}$ sebagai harga saham selama $[0, T]$

Hitung $S_{n}$ yaitu harga saham saat maturity

time

Hitung payoff

Jika MC standar, maka

Jika opsi call, maka

Vprice $=\exp (-r * n / N) * \max (A-K, 0)$

lainnya,

Vprice $=\exp (-r * n / N) * \max (K-A, 0)$

Hitung mean dan standar deviasi dari Vprice,

serta selang kepercayaan $95 \%$

lainnya, (kontrol variat)

pilih $Y=\sum_{i=1}^{n} S_{i}$

Jika opsi call, maka hitung

$$
\begin{aligned}
& X=\exp (-r * n / N) * \max (A-K, 0) \\
& \operatorname{Cov}(X, Y) \\
& \operatorname{Corr}(X, Y) \\
& c^{*} \\
& Z=X+c^{*}\left(Y-\mu_{Y}\right)
\end{aligned}
$$

Hitung mean dan standar deviasi dari $Z$, serta selang kepercayaan $95 \%$

lainnya,

$$
\begin{aligned}
& \text { Vprice }=\exp (-r * n / N) * \max (K-A, 0) \\
& \operatorname{Cov}(X, Y) \\
& \operatorname{Corr}(X, Y) \\
& c^{*} \\
& Z=X+c^{*}\left(Y-\mu_{Y}\right)
\end{aligned}
$$

Hitung mean dan standar deviasi dari $Z$, serta selang kepercayaan $95 \%$

Hitung rasio (reduksi)

\section{Hasil Dan Pembahasan}

Untuk menentukan selang kepercayaan serta harga opsi Call dan Put Asia digunakan program Matlab. Program ini menggunakan data fiktif dengan $r=6 \% ; \sigma=0.3 ; T=1 ; S_{0}=15 ; N=$ $252 ; n=100$. Adapun $r$ adalah suku bunga, $\sigma$ adalah volatilitas, $T$ adalah waktu satu tahun kerja, $S_{0}$ adalah harga saham awal, $N$ adalah waktu hari kerja dan $n$ adalah partisi waktu.

Tabel 3. Selang Kepercayaan Opsi Call Asia Monte Carlo Standar K=9

\begin{tabular}{ccccc}
\hline $\mathrm{M}$ & \multicolumn{2}{c}{ Average Price } & \multicolumn{2}{c}{ Average Strike } \\
\hline 10 & 4.9872 & 6.3177 & -0.2050 & 0.6875 \\
\hline 100 & 5.9094 & 6.5492 & 0.5043 & 0.9211 \\
\hline 1000 & 5.8887 & 6.0831 & 0.7038 & 0.8465 \\
\hline 10000 & 6.0156 & 6.0804 & 0.7269 & 0.7719 \\
\hline
\end{tabular}

Tabel 4. Harga Opsi Call Asia Monte Carlo Standar K=9

\begin{tabular}{ccc}
\hline $\mathrm{M}$ & Fixed Strike & Average Strike \\
\hline 10 & 5.6525 & 0.2413 \\
\hline 100 & 6.2293 & 0.7127 \\
\hline 1000 & 5.9859 & 0.7751 \\
\hline 10000 & 6.0480 & 0.7494 \\
\hline
\end{tabular}

Berdasarkan tabel 3 dan tabel 4 di atas, semakin besar langkah $M$, maka selang kepercayaan 95\% semakin kecil, sehingga taksiran harga opsi call Asia untuk fixed strike maupun average strike semakin baik.

Tabel 5. Selang Kepercayaan Opsi Call Asia Monte Carlo Reduksi Varians K=9

\begin{tabular}{ccccc}
\hline $\mathrm{M}$ & \multicolumn{2}{c}{ Average Price } & \multicolumn{2}{c}{ Average Strike } \\
\hline 10 & 7.1584 & 7.1458 & 0.2549 & 1.6207 \\
\hline 100 & 5.7575 & 5.7575 & 0.4718 & 0.8147 \\
\hline 1000 & 6.0332 & 6.0332 & 0.6740 & 0.7982 \\
\hline 10000 & 6.0314 & 6.0314 & 0.7220 & 0.7600 \\
\hline
\end{tabular}

Tabel 6. Harga Opsi Call Asia Monte Carlo Reduksi Varians K=9

\begin{tabular}{ccc}
\hline $\mathrm{M}$ & Fixed Strike & Average Strike \\
\hline 10 & 7.1584 & 0.9378 \\
\hline 100 & 5.7575 & 0.6432 \\
\hline 1000 & 6.0332 & 0.7361 \\
\hline 10000 & 6.0314 & 0.7410 \\
\hline
\end{tabular}

Berdasarkan tabel 5 dan tabel 6 di atas, semakin besar langkah $M$, maka selang kepercayaan 95\% semakin kecil, sehingga taksiran harga opsi call Asia untuk fixed strike maupun 
average strike semakin baik. Teknik reduksi varians terlihat lebih cepat memperkecil selang kepercayaan $95 \%$ dibandingkan metode standar.

Tabel 7. Selang Kepercayaan Opsi Put Asia Monte Carlo Standar K=17

\begin{tabular}{ccccc}
\multicolumn{4}{c}{ Monte Carlo Standar K=17 } \\
\hline $\mathrm{M}$ & \multicolumn{2}{c}{ Average Price } & \multicolumn{2}{c}{ Average Strike } \\
\hline 10 & 0.4797 & 2.0382 & 0.1392 & 1.0961 \\
\hline 100 & 1.7892 & 2.3478 & 0.4318 & 0.7439 \\
\hline 1000 & 1.8052 & 1.9740 & 0.5287 & 0.6294 \\
\hline 10000 & 1.9049 & 1.9594 & 0.5406 & 0.5716 \\
\hline
\end{tabular}

Tabel 8. Harga Opsi Put Asia Monte Carlo Standar K=17

\begin{tabular}{ccc}
\hline $\mathrm{M}$ & Fixed Strike & Average Strike \\
\hline 10 & 1.2589 & 0.6176 \\
\hline 100 & 2.0685 & 0.5879 \\
\hline 1000 & 1.8896 & 0.5791 \\
\hline 10000 & 1.9322 & 0.5561 \\
\hline
\end{tabular}

Berdasarkan tabel 7 dan tabel 8 di atas, semakin besar langkah $\mathrm{M}$, maka selang kepercayaan 95\% semakin kecil, sehingga taksiran harga opsi put Asia untuk fixed strike maupun average strike semakin baik.

Tabel 9. Selang Kepercayaan Opsi Put Asia Monte Carlo Reduksi Varians K=17

\begin{tabular}{ccccc}
\hline $\mathrm{M}$ & \multicolumn{2}{c}{ Average Price } & \multicolumn{2}{c}{ Average Strike } \\
\hline 10 & 1.4303 & 1.6182 & 0.5807 & 1.1102 \\
\hline 100 & 1.9654 & 2.0924 & 0.4797 & 0.7850 \\
\hline 1000 & 1.9720 & 2.0158 & 0.5212 & 0.6124 \\
\hline 10000 & 1.8924 & 1.9078 & 0.5453 & 0.5744 \\
\hline
\end{tabular}

Tabel 10. Harga Opsi Put Asia Monte Carlo Reduksi Varians K=17

\begin{tabular}{ccc}
\hline $\mathrm{M}$ & Fixed Strike & Average Strike \\
\hline 10 & 1.5243 & 0.8455 \\
\hline 100 & 2.0289 & 0.6324 \\
\hline 1000 & 1.9939 & 0.5668 \\
\hline 10000 & 1.9001 & 0.5599 \\
\hline
\end{tabular}

Berdasarkan tabel 9 dan tabel 10 di atas, semakin besar langkah $M$, maka selang kepercayaan $95 \%$ semakin kecil, sehingga taksiran harga opsi put Asia untuk fixed strike maupun average strike semakin baik. Teknik reduksi varians terlihat lebih cepat memperkecil selang kepercayaan $95 \%$ dibandingkan metode standar

\section{Kesimpulan}

Semakin besar banyaknya langkah M, maka semakin memperkecil jarak selang kepercayaan 95\%, untuk menaksir harga opsi Call maupun opsi Put. Dengan menggunakan teknik reduksi varians terlihat lebih cepat memperkecil selang kepercayaan $95 \%$ dibandingkan metode standar.

\section{Daftar Pustaka}

[1] Fu, M. C., Madan, D. B., \& Wang, T. Pricing continuous Asian options: a comparison of Monte Carlo and Laplace transform inversion methods. Journal of Computational Finance, 2(2), (1999). 49-74.

[2] Hull, J.C., Options, Futures, and Other Derivatives (Eighth Edition). Pearson, England. (2012).

[3] Podlozhnyuk, V., \& Harris, M. Monte Carlo Option Pricing. CUDA SDK. (2008).

[4] Pramuditya, S.A., \& Sidarto, K. A. Penentuan Harga Opsi Asia Dengan Model Binomial Dipercepat. Repository FKIP Unswagati. (2013).

[5] Pramuditya, S.A. Perbandingan Metode Binomial dan Metode Black-Scholes Dalam Penentuan Harga Opsi. SAINSMAT, 5(1). (2016).

[6] Seydel, R., Tools for Computational Finance. Springer-Verlag, Berlin. (2002). 